\title{
Teacher Candidate Mental Health and Mental Health Literacy
}

\author{
Jennifer Dods \\ Queen's University
}

\begin{abstract}
Providing teacher candidates with a strong foundation in mental health literacy during their teacher education program is crucial in ensuring novice teachers are prepared to support the mental health needs of their students. In addition to responding to students, teacher candidates are typically at an age when mental health disorders are common and their personal mental health during the program also needs to be considered. In the current study, a survey was conducted with 375 teacher candidates in order to extend our understanding of the personal mental health and mental health literacy of pre-service teachers. Results showed that teacher candidate mental health was similar to the general population, with $77 \%$ reporting positive personal mental health. Teacher candidates did report high levels of stress. Teacher candidates had considerable personal and professional experience with mental health prior to starting the program and reported positive attitudes and moderate levels of knowledge about mental health disorders. Despite considerable experience and a positive perspective, teacher candidates did not feel ready or competent to support the mental health of students. Current teacher education programs should consider building on the knowledge and experience the teacher candidates bring, and enhancing their capacity to translate that knowledge into the classroom setting.
\end{abstract}

Recent awareness and stigma reduction campaigns in both Ontario and Canada (Mental Health Commission of Canada [MHCC], 2012) have led to increased discourse and visibility of mental health in the public domain. Children and youth have been prioritized within government mental health frameworks, and schools have been identified as a critical location for mental health promotion, intervention, and support (Government of 
Ontario, 2011). The proximity that teachers have to their students has led to them becoming de facto members of the mental health team (Doll, Cummings, \& Chapla, 2014). Recognition of the role that teachers play in making a difference in the lives of their students, particularly for those with additional needs, has led to increased responsibilities (Armstrong, 2014; Meldrum, Venn, \& Kutcher, 2009). Educators are aware of mental health needs in their classrooms, yet many report that the lack of training and education on mental health topics along with role expectations, workload, and their own stress leaves them with insufficient time, knowledge, skill, and confidence to adequately take on this added role (Armstrong \& Hallett, 2012; Walter, Gouze, \& Lim, 2006). In addition to the responsibility of supporting others, teachers are also managing their own mental health, with an estimated $20-25 \%$ of the Canadian population dealing with significant mental health problems or mental illness at any given time (MHCC, 2012, 2013). In-service teachers have emphasized the importance of preparing teacher candidates during their pre-professional education to promote and support mental health within their scope of practice (Alasvand, 2014; Walter et al., 2006).

One way to prepare teacher candidates is through a focus on increasing mental health literacy during their teacher education program. Mental health literacy is not a singledimension construct but rather represents the knowledge, attitudes, beliefs, and skills related to mental health that emerge from experience, education, and existing belief systems (Jorm et al., 1997). Higher mental health literacy, that is, more positive attitudes and beliefs and greater knowledge and skill, enables prevention, early recognition and intervention, as well as reduction of stigma associated with mental illness and mental health disorders (Jorm et al., 1997). There is currently little research on the mental health and mental health literacy of teacher candidates, creating a gap for administrators looking to develop programming in teacher education programs. Ongoing efforts to prepare pre-service teachers to support the mental health of students, while at the same time supporting the mental health of the teacher candidates themselves, remain a work in progress. The purpose of this paper is to provide a snapshot of teacher candidate mental health and mental health literacy by reporting descriptive data collected through an online survey at one university in Ontario. Strengthening the body of research on teacher candidate mental health literacy can support decision makers as they look to implement program-level changes.

\section{Mental Health Literacy Among University Students}

When it comes to mental health literacy in higher education, studies from the United Kingdom and Australia indicate that the mental health literacy of post-secondary students overall is low (Furnham, Cook, Martin, \& Batey, 2011; Lauber, Ajdacic-Gross, Fritschi, Stulz, \& Rössler, 2005; Reavley \& Jorm, 2011; Reavley, McCann, \& Jorm, 2012). Students overall do not perceive mental illness as a "real" illness and believe that, for the most part, others can "snap out of it" if they try hard enough, particularly for depression and anxiety (Yager, 2009). They tend to hold the belief that those with severe mental illnesses are unpredictable and more dangerous than the general population. Interestingly, most students (Eisenberg, Downs, Golberstein, \& Zivin, 2009) have moderately positive attitudes yet believe that others hold more stigmatizing and negative beliefs than they personally do. Factors that lead to higher mental health literacy include being female, having a personal mental health diagnosis, having friends or family with mental health 
problems, having more education, and having studied mental health previously or worked with people with similar challenges (Furnham et al., 2011; Furnham, Annis, \& Cleridou, 2013; Lauber et al., 2005; Reavley, Morgan, \& Jorm, 2014).

As mentioned, personal experiences with mental health play a role in developing mental health literacy. One third of respondents in the United Kingdom stated their main source of information about mental health came from personal experiences (Wolff, Pathare, Craig, \& Leff, 1996), and more recent work adds further weight to the influence of personal experience on mental health literacy (Furnham et al., 2013; Reavley et al., 2014). Personal experience has also been found to be associated with beliefs, attitudes, attributions, and help seeking related to mental health, with a correlation between increased personal experience and favourable attitudes, less stigmatizing beliefs, and greater help seeking (Boyd, Katz, Link, Phelan, 2010; Dahlberg, Waern, \& Runeson, 2008; Jorm, 2012). In addition to the information they receive from their professors during their teacher education program, teacher candidates also bring personal and professional experiences with mental health and supporting others.

Mental health literacy among teacher candidates. In the absence of mental health literacy research with teacher candidates, an exploration of literature on teacher candidates' attitudes and beliefs toward inclusive education provides insight into some aspects of mental health literacy. Overall, teacher candidate attitudes have been shown to be positive toward inclusive education; however, they have been least accepting of those with emotional and behavioural disorders (O'Toole \& Burke, 2013; Romi \& Leyser, 2006). Increased time in personal contact experiences with students with exceptionalities in general has led to more positive attitudes. With respect to students with emotional and behavioural disorders, female teacher candidates have been found to be initially more accepting than males; however, by the end of their program, both males and females were shown to be less supportive of inclusion for this group of students (Romi \& Leyser, 2006), compared to other disorders. This shift was influenced by teacher candidates having entered their teacher education programs with idealized views of favourite teachers and of themselves as teachers. Over the year of study, the mean of positive attitudes toward students, professional development, and self as teacher all decreased with greater acceptance of the reality of the classroom (Chong, 2011). More than half of teacher candidates entered the program having worked with exceptional children or youth, yet only $18 \%$ reported feeling their program had prepared them well to work with students with exceptionalities (Forlin \& Chambers, 2011). Although those who had taken training in special education had fewer concerns about inclusive education, they still did not feel prepared to manage those needs in the classroom (Sokal \& Sharma, 2014). The teacher candidates saw emotional and behavioural disorders as being caused by factors that they could not overcome, and therefore they felt they could have little impact. Due to this prevailing belief, self-efficacy was found to be the strongest predictor of attitudes and beliefs in teacher candidates (Sharma, Loreman \& Forlin, 2012). McCrimmon's (2015) study of teacher education programs in Canada found that increased knowledge about inclusive education and the different disorders students live with, as well as increased experience in inclusive settings, contributed to greater self-efficacy for teacher candidates. Beyond a focus on learning about specific disorders, Kern (2015) spoke to the 
importance of teacher candidates also knowing about positive supports, mentoring, and using relationships to improve emotional and behavioural health.

An exploration of Australian teacher candidate mental health literacy through the use of vignettes led to interesting findings (Armstrong, Price, \& Crowley, 2015) that can be useful for planning. Although the vignettes simply described a student who was experiencing challenges and asked for thoughts on the case, more than $80 \%$ of teacher candidates who were study participants wanted to diagnose the students in the vignette. Fewer than one in five mentioned what they could do as teachers, and many of those who did mention action felt they could handle the issue on their own without additional support. The teacher candidates expressed confidence in discussing a variety of mental health disorders and illnesses but described presentations of poor mental health as bad behaviour. Teacher candidates could identify depression in most cases and schizophrenia in $40 \%$ of cases (Atkinson, 2013).

Mental health literacy in practising teachers. Given the lack of research specific to teacher candidates, further information can be gained from studies on the mental health literacy of in-service teachers. When practising teachers were asked about the major issue they faced in the schools and about preferred topics for professional development, mental health was often suggested (Walter et al., 2006; Whitley, Smith, \& Vaillancourt, 2013). Educators generally have positive attitudes toward supporting student mental health, and positive attitudes lead to more success in the classroom, thus reinforcing the attitude (Kelleher, 2014; Sokal \& Sharma, 2014). Despite awareness and acknowledgement of the need and a positive attitude toward mental health, the majority of teachers report that they do not intervene or act to support student mental health (Koller, 2006; Walter et al., 2006). Insufficient knowledge, a sense of being unprepared, and a lack of the necessary skills to appropriately support students' mental health have been shown to contribute to low selfefficacy and inaction (Romi \& Leyser, 2006; Walter et al., 2011). One approach that has potential to increase teacher efficacy in supporting students is workshops (Kutcher, Bagnell, \& Wei, 2015; Woods \& Rodger, 2014). For example, offering teachers a fiveweek professional learning community experience was found in one study to increase selfefficacy, although it did not decrease teacher stress (Vickery \& Gray, 2014). Although many teachers see providing support as part of their role, their intended behaviour and actual practice have been shown to be influenced far more by their self- efficacy with respect to mental health than by their attitudes or beliefs (Rothi, Leavey, \& Best, 2008).

Approaches to education and training in pre-professional programs must take into account not only the mental health literacy required, but also the psychological resources required to support the mental health of professionals who are supporting others through their practice. For teacher candidates, who are typically enrolled in Bachelor of Education programs at the post-secondary level, relevant research can be drawn from studies focusing on university students.

\section{Personal Mental Health of University Students}

University students are in a high-risk age group for the development of mental health problems, with $75 \%$ of all mental health problems having their onset before the age of 24 (Yager, 2009). With added awareness campaigns, help seeking in this age group is slowly 
increasing and, in some cases, overwhelming the capacity of counselling services at postsecondary institutions (Colleges Ontario, 2012; Popovic, 2012). In Australia almost one fifth of post-secondary students had a diagnosed mental illness and between $48-67 \%$ selfreported mental health problems, yet only one in ten students had sought professional support (Furnham et al., 2011; Reavley et al., 2012). Barriers to help seeking have been identified as negative past experiences, difficulty identifying or explaining symptoms, confidentiality concerns, lack of trust in providers and lack of belief they could help, expense, and a stigmatized belief that they should be able to deal with their own mental health on their own without relying on others (Gulliver, Griffiths, \& Christensen, 2010). It is unknown whether teacher candidates experience similar barriers and struggle with poor mental health without adequate support.

In a large-scale survey undertaken in both Canada and the United States (American College Health Assessment [ACHA]), students reported that the primary influence on their academic success was their mental health (MacKean, 2011), with stress playing a key role. In the 2013 edition of the ACHA, 45\% of Canadian post-secondary students surveyed reported more than average stress and $12 \%$ reported tremendous stress, with $38 \%$ stating that their stress levels affected their academic performance. Beyond stress, participants also reported overwhelming anxiety $(35 \%)$, depression $(20 \%$, ) hopelessness (30\%), and anger (22\%). The ACHA study (2013) did ask participants about help seeking and, encouragingly, $18 \%$ had seen a mental health professional, and almost 1 in 7 had used campus mental health counseling services. More than three quarters reported they would consider seeing a mental health professional if they had a personal problem that was really bothering them.

\section{Preparing Teacher Candidates for Mental Health in the Classroom}

Efforts by school boards to offer professional development to teachers on mental health and well-being and on mental illness are seen as beneficial but inadequate (Armstrong \& Hallett, 2012), highlighting the need to ensure that teachers entering the profession have a foundational knowledge of mental health. The main concerns that inservice teachers express are lacking preparation and training, lacking experience and confidence, and feeling as though the expectations are outside of their scope of practice (Walter et al., 2011). The literature that does exist provides strong support for positioning teacher education programs to build increased knowledge and self-efficacy in mental health to better prepare graduates to support student mental health. Kemp and Hazel (2013) studied the effects of training about mental health in pre-service education and found it did increase mental health literacy. The research also found that although teachers supported mental health in principle and identified it as important, this did not translate into action in terms of their willingness or preparedness to be involved. Approaches to increasing mental health literacy that were found to be effective in preservice education included building connections between mental health and teaching and learning, and focusing on relationships, well-being, impact and outcomes and self-care as meaningful connections between mental health and teaching practice (Kemp \& Hazel, 2013). When mental health was embedded into teacher education, it was found to lead to increased confidence, more accurate understanding of mental health and illness, more positive attitudes, and increased monitoring of their own mental health. Teacher 
candidates with more positive mental health during their time in school had better engagement in the workforce after graduation (Reavley et al., 2012). In addition, one university's efforts to include mindfulness in their teacher education program had a positive impact and were well received (Soloway, 2011).

The need for mental health content has been broadly recognized; however, the challenge has been for Faculties of Education to find time and space to add mental health literacy to an already full curriculum. A number of Canadian universities have worked to offer courses in student mental health or to integrate mental health literacy information into pre-existing courses (Climie, 2015; Hughes, Lafflier, Mamol, Morrison, \& Petrarca, 2015). The majority of mental health content in teacher education programs results from personal inclusion by instructors, as only two Canadian universities have mandated mental health in their teacher education programs (Climie, 2015). An examination of teacher education programs found that often the training on mental health focused on legalities and selfprotection rather than on interventions and ways to support student learning, leading to few teacher candidates feeling adequately prepared (Rodger et al., 2015). Recommendations have been to focus on what challenges the students present (rather than diagnosis) and on how to support those, and on teacher actions and collaborations (Armstrong et al., 2015). Establishing a baseline understanding of the mental health and mental health literacy of Canadian teacher candidates is crucial for development of pre-service education curriculum and for preparing graduates to enter the teaching profession.

\section{Method}

\section{Participants}

Participants in this study were 385 pre-service teachers recruited from an eightmonth Bachelor of Education program at a Faculty of Education in Ontario, Canada. All teacher candidates registered in the B.Ed. program at the time of the study were invited to participate during the final month of their program. Teacher candidates had taken a required half-credit module on inclusive education; however, any discussion of mental health would have been at the discretion of instructors.

\section{Measure}

The authors of the literature on mental health literacy speak to the importance of using a solid theoretical base for work looking at the effective components of mental health literacy (Kelly, Jorm, \& Wright, 2007) and identify the Theory of Planned Behaviour (TPB; Ajzen, 1991) as one such base. TPB has previously been applied in education (Hamilton-Roberts, 2012; MacFarlane \& Woolfson, 2013) to understand attitudes, beliefs, and perception of behavioural control related to the professional practice of educators and to health behaviours, and was used as a theoretical framework to guide the development of the survey measure. The direct (and indirect) variables in TPB that predict intention are attitudes (behavioural beliefs), subjective norms (normative beliefs), and perceived behavioural control (control beliefs). The overlap between the TPB variables and the constructs of mental health literacy (attitudes, beliefs, competencies, self-efficacy) support its use. Background factors that were also surveyed included personal mental health (stress, experience with mental health problems) and stressors, 
training and education in and outside the B.Ed. program, life experience, perceived knowledge and preparation, and mental health experience within classroom placements.

The questionnaire that was developed incorporated demographic questions, questions on attitudes, norms, perceived behavioural control, and beliefs based on the Theory of Planned Behaviour (Ajzen, 1991, 2006, 2011) as well as background questions related to knowledge, preparedness, experience, and personal mental health. Demographic questions included age, gender, program details, and workshop experience. In the education literature, social, emotional, and behavioural (SEB) disorders and social and emotional learning (SEL) are also frequently used to describe mental health. For the purpose of this study both the terms mental health and social, emotional, and behavioural were used.

Using the published manualized approach (Francis et al., 2004) for the TPB, an elicitation study and a pilot study were undertaken with teacher candidates from a previous cohort. The qualitative data from the elicitation study was used to develop the content of the questions for the pilot study survey. An analysis of the pilot study data led to a refinement and shortening of the survey measure for the data collection. The final survey was reviewed by key stakeholders and contained the sections described below. Mental health literacy, as defined in the current study, comprised the elements of attitudes, behavioural beliefs, perceived behavioural control, and control beliefs as identified within the TPB (Ajzen, 1991). The assessment of mental health literacy also captured elements of knowledge, preparation, and experience, both within and beyond the B.Ed. program.

Attitudes, beliefs, and perceived behavioural control Questions on attitudes focused on the perceived instrumentality of the behaviours (harmful-beneficial; unimportant-important) as well as on the associated positive or negative experience (unrewarding-rewarding, unenjoyable-enjoyable). Participants were asked to respond to items using a 7-point semantic differential scale (very negative to very positive). Behavioural beliefs were assessed using items focused on outcomes of actions to support mental health, for example, "My efforts to support mental health/SEB make a difference in the lives of my students." Responses were provided using a 7-point scale ranging from strongly disagree to strongly agree. Items related to perceived behavioural control assessed participants' perception of competence or ability to perform the behaviour and was based on self-efficacy and perceptions of the required (internal and external) resources. An example of a question addressing perceived behavioural control is: "Whether or not I support student mental health/SEB is entirely within my control." Respondents estimated behaviour control along a 7-point scale ranging from strongly disagree to strongly agree. Finally, items related to control beliefs captured a belief that potential barriers and obstacles can be overcome, for example, "I have sufficient time to support student mental health/SEB." Responses were again completed along a 7-point scale ranging from strongly disagree to strongly agree.

Perceptions of knowledge, preparation, and experience. Perceptions of knowledge and preparation related to specific mental illnesses (e.g., depression, anxiety) and mental health topics (e.g., grief/loss, suicide intervention) as well as to life experience, with these topics measured using a 4-point Likert scale (1=none to $4=$ extensive).

Personal mental health. An overall rating of personal mental health $(1=$ very poor to $6=$ excellent $)$, stress levels $(1=$ none to $5=$ tremendous $)$, and questions about the 
impact of specific stressors (e.g., relationship difficulties, finances) on personal and academic life were asked in order to determine overall personal mental health.

\section{Procedure}

Ethical approval for this study was obtained from the appropriate research ethics board. The survey was administered via iPad to teacher candidates during one of their classes after permission was obtained from course instructors. Efforts were taken to ensure that teacher candidates were only in one class in which data collection took place. Posters and brief recruiting talks were used to recruit participants and to give all teacher candidates the opportunity to participate. Participation was voluntary, and teacher candidates were given the survey web-based link should they prefer to complete the survey at home on their own time. Consent was obtained in the survey itself through active completion of a checkbox stating, "I agree to participate in this research" prior to accessing the survey. Letters of information were included above the consent box and were also available in hard copy. All teacher candidates were given a list of mental health resources that could be used to support both their own mental health and that of their students regardless of participation. Once survey data was collected, descriptive analyses of all of the variables were conducted using SPSS v 23. Pearson correlations were next used to examine the relationship between variables.

\section{Results}

\section{Demographics}

The 385 participants represented $58 \%$ of all enrolled candidates and were reflective of the teacher education program year cohort in gender and entry to the program (consecutive or concurrent). More Primary/Junior $(\mathrm{P} / \mathrm{J})$ than Intermediate/Senior $(\mathrm{I} / \mathrm{S})$ students completed the survey, reflective of challenges scheduling survey completion for I/S students. Specifically, approximately $60 \%$ of the survey participants were enrolled in the $\mathrm{P} / \mathrm{J}$ program compared to closer to $50 \%$ enrolled in the program in total. The majority of participants were under age 24 (71\%), with $20 \%$ in the $25-30$ age range and $9 \%$ over 30. Almost half (48\%) of participants indicated they had taken at least one workshop related to mental health. In addition to their undergraduate degree, $10 \%$ of participants also had a college diploma and $6 \%$ had a graduate degree.

\section{Personal Mental Health}

The majority of respondents (77\%) described their mental health as good (38\%), very good $(34 \%)$, or excellent $(5 \%)$. Almost half of the teacher candidates $(46 \%)$ reported they did not experience a mental health problem during their B.Ed. year, and a further $25 \%$ reported they had a problem but had accessed adequate support. Only $4 \%$ did not know where to go to access support. The remaining $25 \%$ of respondents reported experiencing a mental health problem with perceived inadequate support (9\%), or they did not want support (16\%). When seeking support, family, friends, and partners were the primary supports, although 1 in 4 participants (28\%) had also sought support outside their personal network for their mental health. The most common sources of external support 
were professors/advisors (17\%), spiritual leaders (17\%), campus mental health professionals (13\%), and community mental health professionals (12\%).

Participant stress was high; however, given the demands of the program this was not unexpected. Practicum led to the highest stress, with $38 \%$ reporting higher than average stress and $15 \%$ reporting tremendous stress on practicum days. The school year overall was considered to be tremendously stressful by 1 in 10 participants and more stressful than average by 3 in 10 participants. Respondents reported being personally affected by numerous factors during their school year, although in many cases they managed these stressors without any perceived impact on their academics. The four factors they perceived as affecting their academics the most were: stress (36\%), colds and flus (33\%), anxiety (23\%), and worrying about family and friends $(20 \%)$.

\section{Knowledge, Preparation, and Experience}

The participants had significant life experience with individuals with mental health problems, with only $14 \%$ of teacher candidates reporting no or minimal experience prior to entering the B.Ed. program. The most common contexts for moderate or extensive experience with mental health was with friends (66\%), family (62\%), and self $(53 \%)$. However, many participants indicated they had gained moderate or extensive experience through volunteering (48\%) and paid work $(44 \%)$. Once in the B.Ed. program, participants had further exposure to children and adolescents with mental health disorders and problems, with only $27 \%$ reporting they had no or minimal experience with students with mental health disorders or problems during their B.Ed. practicum placements.

Knowledge. The overwhelming majority of teacher candidates believed they had either moderate or extensive knowledge about healthy living (93\%), stress management $(89 \%)$, anxiety $(86 \%)$, and depression $(84 \%)$. Less than half the participants indicated moderate or extensive knowledge related to bipolar affective disorder $(48 \%)$, developmental disorders $(46 \%)$, family conflict $(44 \%)$, anger/aggression management (42\%), schizophrenia (34\%), suicide intervention (34\%), and crisis intervention (31\%).

Preparation to support others in practice. Results for perceptions of being prepared to support others were similar in pattern to knowledge, although overall teacher candidates had lower ratings for perceived levels of preparation than they did for knowledge, particularly for mental illnesses/disorders. Participants felt they were moderately or extensively prepared to support students with anxiety (73\%), depression (62\%), and attention-deficit/hyperactivity disorder (62\%); and with healthy living (80\%), stress (84\%), mental health promotion (66\%), and grief/loss (62\%). There were also a few areas that had very low levels of feeling moderately or extensively prepared to support students, including schizophrenia (17\%), bipolar disorder (27\%), and suicidal ideation (31\%).

Experience in the B.Ed. program. In practicum placements, students reported the highest levels of moderate to extensive experience with ADHD (66\%), anxiety $(65 \%)$, and stress management $(61 \%)$. Teacher candidates reported lower ratings of moderate to extensive experience supporting students with aggressive behaviour (45\%), poor coping skills (47\%), developmental disorders (46\%), and depression (30\%). Education and training within the B.Ed. program on mental health and mental illness/disorders was an 
area that teacher candidates reported was touched on, but only minimally for most topics. Participants did note more moderate or extensive education on some topics in the B.Ed. program including ADHD (45\%), mental health promotion (42\%), healthy living $(37 \%)$, stress management $(31 \%)$, and anxiety $(29 \%)$, paralleling what they saw in practicum. When asked about their interests in receiving further education within the B.Ed. program, participants were overwhelmingly positive in wanting more training on almost every topic. The three topics that students wanted to learn the most about were suicidal ideation, crisis intervention, and anger/aggression management.

Life experience. Outside of the B.Ed. program, participants reported a wide range of life experiences (with family, friends or personal experience) with both mental illness and mental health problems. Teacher candidates had the most moderate/extensive experience with anxiety (77\%) and depression (72\%), followed by addiction (47\%), ADHD (40\%) and eating disorders $(37 \%)$. With regard to mental health problems, participants reported moderate or extensive experience supporting others with stress $(87 \%)$, unhealthy lifestyle choices (64\%), grief/loss (62\%), and through crisis situations (54\%).

Attitudes, beliefs, and perceived behavioural control. Overwhelmingly, teacher candidates reported positive attitudes toward supporting student mental health $(M=$ $6.19 / 7, S D=0.93$ ). Internal consistency for the attitudes scale was acceptable (Cronbach $\alpha=0.70$ ). Teacher candidates saw supporting mental health as important and beneficial for students. The majority of participants indicated they found supporting student mental health to be rewarding and a satisfying aspect of teaching. Behavioural beliefs were also generally positive $(M=5.44 / 7, S D=0.64)$ and the scale had high internal reliability (Cronbach's $\alpha=0.77)$. Almost all participants strongly agreed $(67 \%)$ or agreed $(31 \%)$ that supporting student mental health would lead to better overall academic outcomes; and similar numbers strongly agreed $(58 \%)$ or agreed $(36 \%)$ that it would make a positive difference in the lives of their students. Teacher candidates were less likely to believe that students would respond positively to their efforts to support mental health (strongly agree, 15\%; agree, $38 \%$ ). Almost $60 \%$ of participants believed that for their efforts to benefit students, they had to really know what they were doing in regard to supporting mental health; and 20\% reported that supporting mental health would keep them from meeting the needs of other students.

Teacher candidates were less sure of their ability to control factors in their classroom that would enable them to support student mental health. Internal consistency for the perceived behavioural control and control beliefs scales was high (Cronbach $\alpha=0.73$ and 0.83 respectively). The mean scores were lower than the attitude scores for both control beliefs $(M=4.13 / 7, S D=0.84)$ and perceived behavioural control $(M=4.66 / 7, S D=$ $1.04)$. A third of students either agreed $(24 \%)$ or strongly agreed $(8 \%)$ that supporting student mental health was within their control. Control beliefs had the lowest mean scale score, with teacher candidates identifying a lack of confidence and competence in putting their knowledge into practice in the classroom setting. More detail on the control belief items with low agreement are provided in Table 1. Lacking sufficient knowledge and training to support mental health had the lowest reported agreement. 


\section{Table 1}

\section{Selected Control Belief Items with Low Agreement}

\begin{tabular}{lcc}
\hline Item & $\begin{array}{c}\text { Agree } \\
\boldsymbol{n}(\%)\end{array}$ & $\begin{array}{c}\text { Strongly Agree } \\
\boldsymbol{n}(\%)\end{array}$ \\
\hline $\begin{array}{l}\text { I have sufficient knowledge to support the } \\
\text { mental health of my students }\end{array}$ & $57(15.1 \%)$ & $21(5.6 \%)$ \\
$\begin{array}{l}\text { I am confident I can support student mental } \\
\text { health }\end{array}$ & $86(22.7 \%)$ & $27(7.1 \%)$ \\
$\begin{array}{l}\text { I feel prepared to support the mental health } \\
\text { of my students }\end{array}$ & $75(19.7 \%)$ & $20(5.2 \%)$ \\
$\begin{array}{l}\text { I have sufficient training and education to } \\
\text { support student mental health }\end{array}$ & $29(7.7 \%)$ & $10(2.6 \%)$ \\
$\begin{array}{l}\text { I feel I know how to competently support the } \\
\text { mental health of my students }\end{array}$ & $41(10.8 \%)$ & $11(2.9 \%)$ \\
$\begin{array}{l}\text { I have sufficient time to support the mental } \\
\text { health of my students }\end{array}$ & $38(10.0 \%)$ & $11(2.9 \%)$ \\
$\begin{array}{l}\text { I have sufficient privacy to support student } \\
\text { mental health }\end{array}$ & $72(20.0 \%)$ & $21(5.6 \%)$ \\
\hline
\end{tabular}

Note: $N=380$

Mental health literacy. Pearson correlations were calculated for the variables that constitute mental health literacy, namely the elements of the TPB (attitudes, behavioural beliefs, perceived behavioural control, control beliefs) as well as knowledge, preparation, and experience regarding mental health (see Table 2).

Table 2

Correlations Between Mental Health Literacy Variables

\begin{tabular}{|c|c|c|c|c|c|c|c|}
\hline Variables & 1 & 2 & 3 & 4 & 5 & 6 & 7 \\
\hline 1. Attitudes & - & & & & & & \\
\hline $\begin{array}{l}\text { 2. Perceived } \\
\text { behavioral control }\end{array}$ & $.174^{* *}$ & - & & & & & \\
\hline $\begin{array}{l}\text { 3. Behavioural } \\
\text { beliefs }\end{array}$ & $.439^{* *}$ & $.316^{* *}$ & - & & & & \\
\hline 4. Control beliefs & $.204^{* *}$ & $.699^{* *}$ & $.403^{* *}$ & - & & & \\
\hline 5. Knowledge & $.103^{*}$ & $.353^{* *}$ & $.244^{* *}$ & $.494^{* *}$ & - & & \\
\hline 6. Preparation & .095 & $.450^{\star *}$ & $.259^{* *}$ & $.598^{* *}$ & $.749^{* *}$ & - & \\
\hline 7. Life experience & .065 & $.110^{*}$ & $.116^{*}$ & $.155^{\star *}$ & $.583^{* *}$ & $.449^{* *}$ & - \\
\hline $\begin{array}{l}\text { 8. Practicum } \\
\text { experience }\end{array}$ & .062 & $.141^{* *}$ & $.171^{* *}$ & $.277^{* *}$ & $.350^{* *}$ & $.336^{* *}$ & $.562^{* *}$ \\
\hline
\end{tabular}

Note: ${ }^{*} p<.005,{ }^{* *} p<.001$ 
Significant correlations were found among many of the variables with the strongest relationships observed between perceived behavioural control and control beliefs $(r=.70$, $\mathrm{p}<.001)$, and preparation and knowledge $(\mathrm{r}=.75, \mathrm{p}<.001)$.

\section{Discussion}

Given the lack of extant literature, these findings present a snapshot of descriptive evidence of the personal mental health of pre-service teachers, and a more nuanced understanding of mental health literacy among this population.

\section{Personal Mental Health}

Teacher candidates are informed early in their program of the "many hats" they will wear in their role as educators. Supporting students is a common theme in teacher education, be it with respect to learning, inclusion, achievement, well-being, or mental health. While supporting others is essential, what is sometimes missed is the importance of self-care. Not all stress is detrimental to the achievement of teacher candidates; however, the importance of ensuring that teacher candidates have access to supports must be emphasized. Participants reported mental health similar to that of the general public and of other university students, with approximately 1 in 4 experiencing poor mental health (MHCC, 2012). On a positive note, three quarters $(77 \%)$ of teacher candidates reported good, very good, or excellent mental health at the time of the survey. Another encouraging sign was that more than half of the participating teacher candidates said they had sought out support for their mental health from family, friends, or professionals during the year. This openness to talking about mental health contrasts with the research on the barriers to help seeking and the statistic often cited in relevant literature of 1 in 10 seeking help (Furnham et al., 2011; Gulliver et al., 2010; Reavley et al., 2012). In the study sample, $7.7 \%$ had received mental health support from university counselling services during the past year, lower than the 15.8\% reported by the ACHA study (2013) of university students across Canada. Considering how full the teacher education schedule is and the quantity of time they spend off campus in classroom placements, it is not unexpected that they would seek other sources. In this study $7 \%$ saw a community professional, 9.5\% spoke with faculty or staff about their mental health, and $10.1 \%$ sought spiritual support. Although family and friends outside of the B.Ed. program were the main sources of support, more than half of respondents reached out to their fellow B.Ed. students, increasing support close to them. Having these connections is a sign that teacher candidates have developed supportive friendships even though many have known each other only for the duration of the eight-month program. This may indicate that teacher candidates do not hold the stigmatizing beliefs that keep other university students from reaching out for support (Gulliver et al., 2010). A low percentage of students (4\%) reported that they wanted support but didn't know where to access it, an indicator that oncampus efforts to raise awareness about mental health supports are successful.

Sources of stress within the program were twofold, according to participants. One was the demands of the program itself, and teacher candidates reported finding practicum placements to be particularly stressful; and the second was life stressors and responsibilities. Overall, the study participants reported lower levels of stress $(33 \%$ 
higher than average stress, 9.7\% tremendous stress) compared to the ACHA (2013) reference group ( $45 \%$ higher than average stress, $12 \%$ tremendous stress). As teacher candidates are in at least their fifth year of university (with a four-year undergraduate degree as an entry requirement) or are returning to school, it is proposed that they may have developed more refined stress management strategies, as participants perceived their knowledge of stress management and mental health promotion to be high. The second source of stress was through life events and responsibilities, with almost three quarters of participating teacher candidates reporting being affected by concern for troubled family and friends, far higher than the $40 \%$ reported by their university peers (ACHA, 2013). Teacher candidates are entering a helping profession, and relatedly may tend toward being sources of support for family and friends. A focus on peer support and available resources for supporting others, as well on as self-care, should be a key aspect of mental health promotion initiatives on campus. Teacher candidates in the study were also more affected than their university counterparts by anxiety, cold and flus, financial stress, and extra-curricular activities. Even though they were more involved in extracurricular activities and employment, and had more financial stress than their larger cohort of university peers, these issues had less perceived impact on their academics demonstrating potentially better management strategies. What the study participants did perceive as affecting their academics was anxiety. Strategies and resources to manage anxiety should be made available to teacher candidates, as teaching anxiety can further decrease selfefficacy (Senler, 2016). Teacher candidates also had healthier lifestyles, less insomnia, and were less affected by alcohol and drug use than the reference group (ACHA, 2013).

In developing programming, key points to consider are that although a significant percentage of teacher candidates were dealing with anxiety and depression and other mental health challenges, they were as healthy as their peers and sought support as needed. Stress levels were high but no higher than those of other university students. While there were some differences in what affected teacher candidates personally, they were better able than their peers to keep those challenges from impacting them academically. Primarily they saw their academics being impacted by stress, anxiety, and concern for others. They also were sick more often and lost more school time due to physical illness, further adding to their stress.

\section{Knowledge, Preparation, and Life Experience}

When it came to knowledge, participating teacher candidates were more knowledgeable about internalizing disorders than about other mental health disorders. This is similar to the findings of Armstrong et al. (2015), who reported that teachers were most likely to identify depression. The reason for this is not clear, although one possibility could be Armstrong's (2014) assertion that teachers could easily recognize externalized behaviour but identified it as negative behaviour and not as related to mental health. Another is the influential role of personal experience and greater familiarity with internalizing disorders. Many of the participants had entered the program with moderate to extensive personal and professional experience and drew heavily on that for their knowledge. They reported personal experience as being the main influence in the development of their perceived knowledge. This fits with research on mental health literacy and the importance of experience in the development of knowledge and beliefs 
(Jorm et al., 1997). Since depression and anxiety are two of the most common mental illnesses (MHCC, 2013), it would follow that these were also the illnesses teacher candidates reported having the most experience with and exposure to in their lives.

These findings lead to two important thoughts for further exploration. An enhanced focus on understanding what lies behind challenging behaviour could lead to a greater understanding of the presentation of externalizing disorders and to a shift in the perception of these disorders toward being mental health related (Armstrong et al., 2015). It is also important to build on the experience that teacher candidates bring with them when they enter their teacher education. Time could be directed toward translating that knowledge and personal and professional experience into the classroom setting and into the role of the teacher. In parallel to studies on inclusion, knowledge did not necessarily lead to competence in practice (Sokol \& Sharma, 2014). Participants perceived themselves as having more knowledge than preparation, and increasing the opportunities to discuss their knowledge in scenarios specific to the classroom could increase perceived preparation. The majority wanted significantly more mental health content on all subjects, similar to in-service teachers (Walter et al., 2011). The greatest need was for information about crisis situations including suicidal ideation, anger, and aggressionsituations that student did not encounter frequently, but that they felt were important to be prepared for given the risk involved. There also remained a group of participants with very little experience and knowledge and who would be better served by more explicit or basic-level instruction on mental health. Offering more than one course on mental health may be a way to address this diverse range of perceived knowledge and life experience among teacher candidates.

An interesting correlation to note was that participants with greater life experience with mental health also had more practicum experience with mental health $(\mathrm{r}=.562$, $p<.001)$. The reasons for this are unknown; however, it could be postulated that those who had more exposure to mental health may have chosen practicum placements that were mental health related or they may have been more aware of mental health issues in the placements they were in. This creates further separation in experience, as some participants had both life and classroom experience, while another subset of teacher candidates had little life experience or practicum experience as they entered the teaching profession. Most placements include students with mental health problems, so ensuring that teacher candidates with less life experience have opportunities to reflect on and explore mental health issues (which may not be as overt as they expect) in the classroom may help to increase their awareness.

\section{Mental Health Literacy}

Significant correlations were found among experience, knowledge, and feeling prepared, similar to findings on teacher candidates supporting students with developmental disabilities (Hutchinson et al., 2015) and on mental health literacy in the general population (Jorm, 2012).

Knowledge is central to the development of self-efficacy and to feeling prepared. For the teacher candidates in this study, the only significant contributor to knowledge was life experience. However, it is known that further education and training can also increase 
knowledge (Woods, 2014). Since knowledge has not on its own been directly related to action, it is possible that the knowledge gained by training and education is a different type of knowledge than that gained by life experience. In this study, knowledge gained through life experience led to increased perceived preparation and increased control beliefs. Action is known to be mediated by self-efficacy, and it is possible that hands-on experience creates knowledge that is easier to translate and use in practice compared to the acquisition of knowledge through training and education. Although participating teacher candidates reported being knowledgeable about specific mental health disorders and illnesses, they did not feel they had the knowledge necessary to act and to support student mental health. This suggests that a greater focus on acquiring knowledge about mental health problems during practicum placements may be needed to support the translation of knowledge into the classroom setting. An increased focus on knowledge specific to the classroom setting might build self-efficacy and strengthen the belief that supporting student mental health is within the control of the teacher candidate.

The positive attitudes toward mental health and supporting students is promising and in line with teacher candidate attitudes toward inclusion (MacFarlane \& Woolfson, 2013). Overall teacher candidates wanted to help students and believed that supporting student mental health would improve both academic outcomes and overall well-being. Very few teacher candidates held stigmatizing beliefs that would prevent them from supporting students, although similar to other research (Eisenberg et al., 2009), they did perceive that others in the education field held more stigmatizing beliefs about mental health than themselves. Despite the positive attitudes and beliefs, teacher candidates struggled with perceived behavioural control and their ability to support student mental health. They did not feel ready or prepared and saw time, workload, and privacy as barriers that would keep them from acting on their beliefs. Also missing was perceived competence to support students in the classroom. Despite reporting moderate levels of knowledge, participating teacher candidates overwhelmingly wanted more education and training on mental health in their B.Ed. year. Their mental health literacy was primarily lacking in the area of skill and competence for some, although for many teacher candidates experience and or knowledge was also missing.

In summary, the findings suggest that the personal mental health of teacher candidates is similar to that of other university students and to the population in general. Despite their stress and anxiety levels being high, teacher candidates are more successful than their peers at managing the stress in a way that lessens the effects on their academics. Teacher candidates enter the program with moderate personal and professional life experience with mental health problems and take on the role of a being a support for family, friends, and fellow teacher candidates who are struggling. They report positive attitudes toward supporting students with mental health problems; and while they have considerable knowledge about specific mental illnesses and needs, they struggle to feel prepared to translate this knowledge into the classroom environment or to feel competent to support mental health in their role as educators. 


\section{Conclusion}

As teacher candidates prepare to enter the ever-evolving and expanding professions of education, the findings from this study can be used to better prepare them for the task at hand. Knowing what areas are most affecting their mental health and their academics can guide the development of supports and resources available to teacher candidates. It is also an important reminder to not lose sight of the personal mental health of those in the process of learning how support the mental health and well-being of others. Also highlighted by this data is the value in contextualizing the knowledge teacher candidates bring to the classroom setting and to the role of educators. Much of the experience the teacher candidates have related to mental health is from life experience outside of a classroom, and the findings suggest that it can be challenging for students to translate that experience to the context of the classroom and to their role as educators. Knowledge alone is not sufficient for ensuring teacher candidates feel prepared and confident in supporting student mental health; they need hands-on experience and deeper reflection on mental health in their students. Understanding the current state of their mental health and mental health literacy is an important first step in refining and implementing mental health education in pre-professional practice.

\section{Limitations and Future Research}

The findings in this study should be interpreted with caution, as participants were from one institution in Ontario and may not be reflective of teacher candidates in other locations or programs. As part of the program entry requirements, participants had to submit a statement of experience, and this may explain the high percentage of participants who had significant experience in areas of mental health. Due to the selfreport design, findings are only representative of teacher candidates' perceptions of their own knowledge and preparation, and without independent testing of those variables, it is impossible to know by what measure they are assessing their own knowledge.

In addition, the survey measure was designed using a manualized process and tested through a pilot study but remains an unvalidated tool. Further testing on this tool would strengthen conclusions. In addition, while using the Theory of Planned Behavior framework to explore mental health literacy makes sense due to parallel variables, the overlap between the TPB framework variables and mental health literacy variables has not been tested.

Based on the present findings, there are three areas of research that would be of value to pursue. Exploring the translation of knowledge gained from life experience to the practice of supporting students in the classroom setting could lead to activities in the teacher education program that actively create that bridge. Deepening our understanding of the process of moving from knowledge about mental health and mental health problems to the mobilization of that knowledge into the classroom to support students would be very valuable. Secondly, understanding the learning needs of students who have both life and practicum experiences with individuals with mental health problems and of students with minimal life or practicum experience could increase the utility of differentiated information offered in the teacher education program. Finally, research investigating the outcomes of mental health curricula delivered as part of the B.Ed. 
program would be of value. Identifying what aspects of mental health curricula in teacher education programs make the most difference in terms of perception of preparedness once candidates enter the field of teaching could further maximize the effectiveness of developing programs.

\section{References}

Ajzen, I. (1991). The theory of planned behavior. Organizational Behavior and Human Decision Processes, 50, 179-211.

Ajzen, I. (2006). Constructing a TPB questionnaire: Conceptual and methodological considerations. Retrieved from the website of the University of Bielefeld, Germany, http://www.unibielefeld.de/ikg/zick/ajzen\%20construction\%20a\%20tpb\%20questionnaire.pdf

Ajzen, I. (2011). The theory of planned behaviour: Reactions and reflections. Psychology and Health, 26(9), 1113-1127. doi:10.1080/08870446.2011.613995

Alasvand, S. (2014). Preparing teacher candidates and experienced teachers: Armed to support student mental health and well-being (Unpublished master's thesis). Ontario Institute for Studies in Education of the University of Toronto, Toronto, ON.

American College Health Association (ACHA). (2013). American College Health AssociationNational College Health Assessment II: Canadian reference group data report, spring 2013. Hanover, MD: Author.

Armstrong, D. J. (2014). Educator perceptions of children who present with social, emotional and behavioural difficulties: A literature review with implications for recent educational policy in England and internationally. International Journal of Special Education, 18(7), 731-745.

Armstrong, D. J., \& Hallett, F. (2012). Public face, hidden knowledge: Teachers conceptions of children with SEBD. Educational and Child Psychology, 29(4), 77-87.

Armstrong, D. J., Price, D., \& Crowley, T. (2015). Thinking it through: A study of how pre-service teachers respond to children who present with possible mental health difficulties. Emotional and Behavioural Difficulties, 20(4), 1-13.

Atkinson, E. (2013). Educators as facilitators of mental health: An investigation of the mental health literacy of pre-service teachers (Unpublished master's thesis). Mount Saint Vincent University, Halifax, NS.

Boyd, J., Katz, E. P., Link, B. G., \& Phelan, J. C. (2010). The relationship of multiple aspects of stigma and personal contact with someone hospitalized for mental illness, in a nationally representative sample. Social Psychiatry and Psychiatric Epidemiology, 45(11), 1063-1070.

Chong, S. (2011). Development of teachers' professional identities: From pre-service to their first year as novice teachers. KEDI Journal of Educational Policy, 8(2), 219-233.

Climie, E. (2015). Canadian children's mental health: Building capacity in school-based intervention. Interventions in Schools and Clinics, 51(2), 1-4.

Colleges Ontario. (2012). Focus on mental health (Conference summary). Toronto, ON: Author. Retrieved from http://www.collegesontario.org/policy-positions/health.html

Dahlberg, K. M., Waern, M., \& Runeson, B. (2008). Mental health literacy and attitudes in a Swedish community sample-Investigating the role of personal experience of mental health care. Biomed Central Public Health, 9(8), 8-10. doi:810.1186/1471-2458-8-8

Doll, B., Cummings, J. A., Chapla, B. A. (2014). Best practices in population-based school mental health services. In P. Harrison \& A. Thomas (Eds.), Best practices in school psychology: 
Systems level services (pp. 149-163). Bethesda, MD: National Association of School Psychologists.

Eisenberg, D., Downs, M. F., Golberstein, E., \& Zivin, K. (2009). Stigma and help seeking for mental health among college students. Medical Care Research and Review, 66(5), 522-541.

Forlin, C., \& Chambers, D. (2011). Teacher preparation for inclusive education: Increasing knowledge but raising concerns. Asia-Pacific Journal of Teacher Education, 39(1), 17-32. doi:10.1080/1359866X.2010.540850

Francis, J. J., Eccles, M. P., Johnston, M., Walker, A., Grimshaw, J., Foy, R. ... Bonettti, D. (2004). Constructing questionnaires based on the theory of planned behaviour: a manual for health services researchers. Newcastle upon Tyne, UK: University of Newcastle.

Furnham, A., Annis, J., \& Cleridou, K. (2013). Gender differences in the mental health literacy of young people. International Journal of Adolescent Health, 26, 283-292.

Furnham, A., Cook, R., Martin, N., \& Batey, M. (2011). Mental health literacy among university students. Journal of Public Mental Health, 10(4), 198-210. doi:10.1108/17465721111188223

Government of Ontario. (2011). Open minds, healthy mind-Ontario's comprehensive mental health and addictions strategy. Toronto, ON: Queen's Printer for Ontario.

Gulliver, A., Griffiths, K., \& Christensen, H. (2010). Perceived barriers and facilitators to mental health help-seeking in young people: A systematic review. BioMed Central Psychiatry, 10 (11), 9-15.

Hamilton-Roberts, A. (2012). A proposed model for predicting the willingness of mainstream secondary teachers to support the mental health needs of pupils (Unpublished doctoral dissertation). Cardiff University, Cardiff, UK.

Hughes, J., Laffier, J., Mamol, A., Morrison, L., \& Petrarca, D. (2015). Re-imagining pre-service teacher education in Ontario, Canada: A journey in the making. Higher Education in Transformation Conference, Dublin, Ireland, 436-446.

Hutchinson, N., Minnes, P., Burbidge, J., Dods, J., Pyle, A., \& Dalton, C. (2015). Perspectives of Canadian teacher candidates on inclusion of children with developmental disabilities: A mixed methods study. Teacher Education and Special Education, 25, 42-64.

Jorm A. F. (2012). Mental health literacy: Empowering the community to take action for better mental health. American Psychologist, 67(3), 231-243.

Jorm, A. F., Korten, A. E., Jacomb, P. A., Christensen, H., Rodgers, B., \& Pollitt, P. (1997). "Mental health literacy": A survey of the public's ability to recognise mental disorders and their beliefs about the effectiveness of treatment. Medical Journal of Australia, 166, 182-186.

Kelleher, S. (2014). Teacher's beliefs about mental health issues (Unpublished doctoral dissertation). California State University, San Bernardino, CA. Electronic Thesis Projects and Dissertations, Paper 16.

Kelly, C., Jorm, A., \& Wright, A. (2007). Improving mental health literacy as a strategy to facilitate early intervention for mental disorders. Medical Journal of Australia, 187(7), S26-S30.

Kemp, E., \& Hazel, G. (2013). From evidence to practice and the crucial period in between: Mental health promotion, mental ill-health prevention, early intervention and suicide prevention in pre-service teacher training is vital to ensure a skilled workforce. Proceedings of the Australian Teacher Education Association (ATEA) Conference. Sydney, Australia: Australian Teacher Education Association.

Kern, L. (2015). Addressing the needs of students with social, emotional and behavioural problems: Reflections and visions. Remedial and Special Education, 36(1), 24-27. 
Koller, J. (2006). Responding to today's mental health needs of children, families and schools: Revisiting the preservice training and preparation of school-based personnel. Education and Treatment of Children, 29(2), 197-217.

Kutcher, K., Bagnell, A., \& Wei, Y. (2015). Mental health literacy in secondary schools. Child and Adolescent Clinic of North America, 24(2), 233-244.

Lauber, C., Ajdacic-Gross, V., Fritschi, N., Stulz, N., \& Rössler, W. (2005). Mental health literacy in an educational elite-An online survey among university students. BioMed Central Public Health, 5(44), 1-9.

MacFarlane, K., \& Woolfson, L. M. (2013). Teacher attitudes and behavior toward the inclusion of children with social, emotional and behavioral difficulties in mainstream schools: An application of the theory of planned behavior. Teaching and Teacher Education, 29, 46-52.

MacKean, G. (2011). Mental health and well-being in postsecondary education settings: A literature and environmental scan to support planning and action in Canada. Toronto, ON: Canadian Association of College and University Student Services. Retrieved from http://www.cacuss.ca /current_projects_mental_health_report.htm

McCrimmon, A. (2015). Inclusive education in Canada: Issues in teacher preparation. Intervention in School and Clinic, 50(4), 234-237.

Meldrum, L., Venn, D., \& Kutcher, S. (2009). Mental health in schools: How teachers have the power to make a difference. Health \& Learning Magazine, 8, 3-5.

Mental Health Commission of Canada (MHCC). (2012). Changing directions, changing lives: the mental health strategy for Canada. Calgary, AB: Author.

Mental Health Commission of Canada (MHCC). (2013). Making the case for investing in mental health in Canada. Calgary, $\mathrm{AB}$

O'Toole, C., \& Burke, N. (2013). Ready, willing and able? Attitudes and concerns in relation to inclusion amongst a cohort of Irish pre-service teachers. European Journal of Special Needs Education, 28(3), 239-253.

Popovic, T. (2012). Mental health in Ontario's post-secondary education system (Policy paper). Toronto, ON: College Student Alliance. Retrieved http://www.collegestudentalliance.ca/wpcontent/uploads/2012/05/Mental-Health-in-PSE-Tamara-Popovic-May-2012.pdf

Reavley, N. J., \& Jorm, A. F. (2011). Young people's stigmatizing attitudes towards people with mental disorders: Findings from an Australian national survey. The Australian and New Zealand Journal of Psychiatry, 45(12), 1033-1039. doi:10.3109/00048674.2011.614216

Reavley, N. J., McCann, T. V., \& Jorm, A. F. (2012). Mental health literacy in higher education students. Early Intervention in Psychiatry, 6(1), 45-52. doi:10.1111/j.1751-7893.2011.00314.x

Reavley, N. J., Morgan, A. J., \& Jorm, A. F. (2014). Development of scales to assess mental health literacy relating to recognition of and interventions for depression, anxiety disorders and schizophrenia/psychosis. Australian and New Zealand Journal of Psychiatry 48, 61-69.

Rodger, S. Hibbert, K. Leschied, A., Pickel, L, Stepien, M. Atkins, ... Vandermeer, M. (2015). Shaping a mental health curriculum for Canada's schools: Rationale and a brief overview. Physical and Health Education Journal (PHE) 80(3), 28-29.

Romi, S., \& Leyser, Y. (2006). Exploring inclusion pre-service training needs: A study of variables associated with attitudes and self-efficacy beliefs. European Journal of Special Needs Education, 21(1), 85-105. doi:10.1080/08856250500491880

Rothì, D. M., Leavey, G., \& Best, R. (2008). On the front-line: Teachers as active observers of pupils' mental health. Teaching and Teacher Education, 24(5), 1217-1231. 
Senler, B. (2016). Pre-service science teachers' self-efficacy: The role of attitude, anxiety and locus of control. Australian Journal of Education, 60(1), 26-41.

Sharma, U., Loreman, T., \& Forlin, C. (2012). Measuring teacher efficacy to implement inclusive practices. Journal of Research in Special Educational Needs, 12(1), 12-21.

Sokal, L., \& Sharma, U. (2014). Canadian in-service teachers' concerns, efficacy, and attitudes about inclusive teaching. Exceptionality Education International, 23(1), 59-71.

Soloway, S. (2011). Preparing teacher candidates for the present: Exploring the praxis of mindfulness training in teacher education (Unpublished doctoral dissertation). University of Toronto, Toronto, ON.

Vickery, N., \& Gray, T. (2014). The effects of professional experience upon pre-service physical and health education teacher's resilience, self-efficacy and stress. University of Sydney Papers in HMHCE , 3, 17-46. Retrieved from http://sydney.edu.au/education_social_work/research/ centres_and_networks/ADPN/HMHCE-papers/resources/HMHCE_Article_02_2014.pdf

Walter, H., Gouze, K., Cicchetti, C., Arend, R., Mehta, T., Schmidt, J., \& Skvarla, M. (2011). A pilot demonstration of comprehensive mental health services in inner-city public. Journal of School Health, 81(4), 185-194

Walter, H. J., Gouze, K., \& Lim, K. G. (2006). Teachers' beliefs about mental health needs in inner city elementary schools. Journal of the American Academy of Child and Adolescent Psychiatry, 45(1), 61-68.

Whitley, J., Smith, D., \& Vaillancourt, T. (2013). Promoting mental health literacy among educators: Critical in school-based prevention and intervention. Canadian Journal of School Psychology, 28, 56-70. doi:10.1177/0829573512468852

Wolff, G., Pathare, S., Craig, T., \& Leff, J. (1996). Community knowledge of mental illness and reaction to mentally ill people. The British Journal of Psychiatry, 168(2) 191-198.

Woods, J. (2014). Evaluating mental health training for teachers: Identifying and supporting students with mental health challenges (Unpublished master's thesis). Western University, London, ON.

Yager, Z. (2009). Developing wellbeing in first year pre-service teachers: A trial of a personal approach to professional education. Journal of Student Wellbeing, 3, 52-72.

\section{Author's Note}

Correspondence concerning this article should be addressed to Jennifer Dods, Queen's University, 146 Stuart St., Kingston, ON, K7L 5C4, Canada. Email: jennifer.dods@queensu.ca 